\title{
Impact of Multimedia Instruction in Biology on Senior High School Students' Achievement
}

\author{
Allan Ayittey ${ }^{1}$, Emmanuel Arthur-Nyarko ${ }^{2, *}$, Francis Onuman $^{3}$ \\ ${ }^{1}$ Department of ICT, Cape Coast Teaching Hospital, Ghana \\ ${ }^{2}$ Department of Maths and Science, College of Distance Education, University of Cape Coast, Ghana \\ ${ }^{3}$ Christian Service University College, Ghana
}

Received September 15, 2019; Revised November 2, 2019; Accepted November 13, 2019

Copyright $(2019$ by authors, all rights reserved. Authors agree that this article remains permanently open access under the terms of the Creative Commons Attribution License 4.0 International License

\begin{abstract}
This study investigated the comparative effectiveness of teaching through the use of interactive multimedia and conventional teaching method in biology on senior high school students concerning students' achievement. The pretest-posttest non-equivalent quasi-experimental design was used for this study. One hundred and ten (110) form three (Form 3) General Science students who had Biology as an Elective subject were selected for the study. They were grouped and labeled control and experimental groups. Students in the experimental group were taught through the use of interactive multimedia whereas the control group was taught through the traditional teaching approach. The study found that both methods were quite effective for teaching Photosynthesis in Biology. However, out of the two methods, the multimedia approach was found more suitable for teaching abstract topics. The study also reported no statistically significant differences in the students' academic performance by gender. These findings suggest that the academic achievements of students in Biology can be improved with multimedia instruction. The study recommends that the computer should be used to complement the teachers' teaching but should not take over the teaching process. A similar study could be carried out in a similar environment but should include more than one topic as this study used only one topic.
\end{abstract}

Keywords Multimedia, Instruction, Biology, Photosynthesis, Academic Performance

\section{Introduction}

All over the world science is regarded as the bedrock of modern-day technology. Nations all over the world, especially the developing countries like Ghana are making frantic efforts to technologically and scientifically develop their economies. This stems from the fact that the world is progressively becoming "scientific" (Quarcoo-Nelson, Buabeng \& Osafo, 2012). Shreds of evidence from the history of education indicates that science has been at the top among all school subjects because of the essential position it occupies in human development, training, and the environment. Educators give special prominence to biology among the sciences because of its educational values, its close relatedness to man as a living organism, its special field of investigation and interconnection with the other sciences (as cited in Yeboah, 2014). As a result of this, Biology is a prerequisite to other professions like medicine, agriculture, dentistry and many others due to the critical position it occupies among the natural sciences. According to Bibby, as cited in Yeboah, (2014), in our modern world controlled by science and technology, there is the need for enough Biology education for every child to ensure their total development for the future. Biology and science, in general, receive a lot of recognition among the courses in the basic and the senior high school levels that suggest accurately the key role played by the subject in modern society. Gambari, Yaki, Gana, and Ughovwa (2014) contend that the importance of the biology is not confined to the development of only people but also for the improvement of the social, economic and political goals of countries all over the world. Umar (2011) explains that Biology is a natural science that is concerned with how the world is arranged, how it functions and what these functions are, how it evolves, "how living things came into being and how they interact with one another and with their environment" (p.25).

Ghana, like most developing countries, not wanting to be left behind in the use of technological innovations, has putative the importance of ICT in its development agenda. The Government of Ghana has therefore placed a strong emphasis on the role of ICT in contributing to the country's economy and education. The country aims to widely 
deploy ICT to facilitate the delivery of educational services at all levels of the educational system to improve the system (Owusu, 2009).

The use of ICT as a means of reaching out to the poor in Ghana has been captured in the country's development agenda like the Ghana Poverty Reduction Strategy Paper (GPRS I \& II) and the Education Strategic Plan 2003-2015 (Mangesi, 2007). Upon the basis of the importance of ICT in the nation's socio-economic agenda, the Government of Ghana with the help of the Government of India has established the Kofi Annan Centre of Excellence in Information Technology to help in accomplishing this agenda (Owusu, 2009). The teaching and learning of ICT has therefore been formally enshrined in the educational system. The new education reform has emphasized the teaching and learning of ICT. These developments underscore the importance the country attaches to the development of ICT. According to the chief examiners' report of the West African Examination Council (WAEC) Ghana, the pure sciences thus Biology, Chemistry, Physics recorded entry of 59,612 candidates combined representing $49.19 \%$ in West African Senior School Certificate Examination (WASSCE, 2006). In some years past, biology as a subject was known to have the highest number of student enrolments in senior high schools. A study conducted by Abdullahi, 1982 (as cited in Yeboah, 2014) indicated that student enrolments in biology from 1977 to 1989 had always surpassed the combined enrolment in other science subjects. These high enrolments in biology figures indicate that biology is popular among the other sciences. However, this number of candidates sitting for the biology paper in WASSCE does not match the students' achievement in the subject. The integration of ICT's and other technologies into teaching and learning can help improve the results of students in biology and other subject areas as far as the WASSCE is concerned.

Currently, multimedia technology utilizes communication media such as videos, computers, and still images in the modern world to achieve its purpose of enhancing teaching and learning. Cockerill, Comeau, Lee, and Vinayak (2015) duly acknowledge the importance of multimedia in learning when they state that it promotes a large variety of teaching styles as well as learning preferences. The usefulness of video technology, particularly in laboratory science, cannot be underestimated as it facilitates the visualization of procedures and allows for more profound understanding than when the same information conveyed through only text. The thrilling effects of multimedia continue to provide every reason for researchers to persistently explore deeper into its application in education and even beyond, thus, the need for this research.

\subsection{Problem Statement}

Since the introduction of the Senior Secondary School
(SSS) programme in 1991 (which is now Senior High School) as part of Ghana's educational reforms in 1987, the Chief Examiners' Reports from the West African Examination Council (WAEC) have consistently indicated poor performance of SHS students in Science (WAEC, $2002 ; 2003 ; 2004 ; 2005)$. Most students fail or get low-quality grades in biology more than in the other science subjects such as physics and chemistry. The Chief Examiners' Reports show that more students fail in biology because the weaknesses that are pointed out year out don't seem to be addressed by the schools (WAEC, 2004 \& 2006). Ineffective methods of teaching employed by teachers have been noted as one of the key factors accounting for the abysmal performance of students in biology (Ahmed \& Abimbola, 2011; Kareem, 2003; Umar, 2011). The conventional teaching method (CTM) primarily comprises of lectures and teacher-directed instructions and takes place in the classroom. CTM is a teacher-centered method that hinges on learning through the guidance of the teacher at all times. In this method, the students' role is to listen to the teachers and learn from them as they teach. CTM eliminates interactivity and the active involvement of students in the lesson as the student just pay attention and listen to the teacher. In the light of this, some researchers (Ahmed, 2008; Ahmed \& Abimbola, 2011; Kareem, 2003; Umar, 2011) warn that CTM does not encourage insightful learning and long-term retention of some abstract concepts in biology. One way of addressing these challenges is through the use of a technology-based instructional system that promotes meaningful learning. Adegoke (2010) and Kuti (2006) advise that the use of multimedia presentations support visual and verbal formats supplemented with pictures, animations, texts, and narrations that could cater to the limitations of CTM.

\subsection{Purpose of the Study}

This study sought to investigate the effect of multimedia instruction on secondary school students' achievement in biology. The study specifically addressed the following research questions.

[1] What are the differences in pretest scores between students taught with multimedia(experimental group) and those thought through the traditional approach to teaching (control group)?

[2] What are the differences in achievement mean scores between students taught using multimedia approach and those taught using the traditional approach in selected schools in Cape Coast metropolis?

[3] What are the differences in achievement mean scores between male and female students exposed to them multimedia approach and those exposed to the traditional approach in selected schools in Cape Coast metropolis?

H01: There is no statistically significant differences in achievement mean scores (post-test scores) between 
students taught using multimedia instruction and those taught using the traditional approach.

H02: There is no statistically significant differences in academic achievement (post-test) mean scores between male and female students taught using multimedia approach and those taught with the traditional approach.

\section{Literature Review}

\subsection{Multimedia in Proper Perspective}

In recent times, multimedia has become a household name among educational technologies. Its uses stretch across many fields including business, education, technology and so on. The term has become widespread with the advent of new and emerging digital technologies. As the term connotes, multimedia perfunctorily means the use of more than one medium to present information. It can also be explained as a computer-directed integration of text, graphics, drawings, images (Video or still), animation, audio, and any other media to digitally represent, store, transmit and process information. As contained in Parekh's study cited in Krstev and Trtovac (2014) multimedia implies "means of communication through multiple media", whereas a multimedia document is "a document (a set of structured information) which comprises information coded in at least one continuous (time-dependent) medium and in one discrete (time-independent) medium" (p.152). Multimedia elements include sound, text, animation, graphics, and image.

Today's multimedia is characterized by the use of authoring software to intelligently blend sound, text, graphics, animation, and video. Another characterizing feature of multimedia is its interactivity. Interactive multimedia can be designed to allow the user to control "when" and "how" the elements are presented and delivered. Education is one of the fields has greatly benefited from the unique advantages of multimedia. They allow teachers to deliver content in various forms to students. In teaching physics with interactive multimedia, Jian-hua and Hong (2012) declare:

Application of multimedia technology can provide students with vivid, clear, realistic emotional material in the classroom, so that students can perceive complete, clear and image physical phenomena which is difficult to observe or achieve, feel many scenes which are impossible in traditional teaching in the classroom, building a physical model with initiative. Moreover, the students can understand physical concepts, laws, and theorems more easily; at the same time, the teaching is easy and the efficiency is increased (p.1898).

Teaching with multimedia can make learning process active, goal-directed and flexible in terms of time and space which is not affected by distance meeting individual learning styles. Slack (1999) state that the application of multimedia in teaching makes interesting and without tension that is sometimes associated with the traditional lecture method. Hence, its impact on the styles of teaching and learning in the classroom is profound allowing for all kinds modifications to teaching.

\subsection{Application of Multimedia to the Teaching and Learning Process}

Many studies have been conducted in Ghana as well as aboard in the area of multimedia. Acha (2009), Kumar (2011) and others have researched into multimedia in the teaching of English and found positive results. Ellaisamy, (2007) also conducted a study by using the multimedia approach to teach Science and found that teaching through multimedia is effective. Many experiments have been done in various subject areas to date to find the effectiveness of multimedia in teaching.

Most of the results show positive outcomes, with students being enthusiastic about new methods of learning. Most of the experiments suggest that multimedia approach to teaching is more effective than the traditional approach to teaching. Taking the findings of such experiments into account, many schools have also started using the multimedia approach to teaching in their classrooms.

The increasing use of multimedia in teaching and learning has led to an increasing interest by researchers and other stakeholders to understand the effect of these technologies on students' learning at all levels of education. Some studies have predicted that innovations in technology would dramatically transform traditional teaching and learning. Multimedia instruction involves improving not only the visual features of the presentation of course content but also makes the learning environments active, encourage positive attitudes to learning abstract and complex concepts, enhance students' achievements and improve communication that suits all learning styles. Multimedia has emerged as a better option for students and yielded significant improvements in students learning.

\subsection{Multimedia in the Teaching of Biology}

The role of Biology as a subject in the school curriculum is cardinal. Biology permeates almost all the science-related courses including biochemistry, medicine, pharmacy, nursing, and the likes. It is therefore necessary that students to venture into these fields should be vested in Biology to be able to achieve their aim. Several studies have revealed that despite the relative importance and popularity of the subject and its prominence in everyday lives, students' performance at the senior high school level has been abysmal (Yususf \& Afolabi, 2010; Ahmed, 2008). Researchers quest to unearth the causes of this appalling academic performance of students in Biology and other science-related courses have attributed the problem to large class sizes, poor methods of teaching as a result of poor 
quality science teachers and insufficient science facilities(Yususf \& Afolabi, 2010; Ahmed, 2008).

One way of tackling these problems that have bedeviled the teaching and learning of science has been the use of computer-assisted instruction. Multimedia is rich in content due to the extensive collection of different media involved in their composition. Research on multimedia in teaching has consistently proven that they can cater for large classes thereby transforming the traditional methods of teaching (Persin, 2002). Although the results on the effect of multimedia teaching and learning have not been consistent, they have always been in favour of technology-assisted learning. According to Feeg, Bashatah, and Langley (2005), the use of multimedia application teaching has yielded significantly better results compared to the conventional methods of teaching. Harris (2002) posits that the use multimedia in teaching "create active learning environments, improve students' performance, foster positive attitudes to learning complex concepts, increase communication and could be adapted to all learning styles and levels of instruction" (p.15). Similarly, Gabari and Yusif (2016) purposively selected two senior secondary school class to undertake a study on the effect of computer-assisted cooperative learning strategy on students' knowledge in physics and retention. It was revealed that the students taught with the use of the computer-assisted Jigsaw II course outperformed and had good retention compared to their counterparts taught with individualized computer instructions. The two methods somehow look related. However, the difference lies in the experimental group using the computer-assisted learning package while the other group used individualized computer instruction. Other studies that reported similar results included Sangodoyin (2010), Klein and Koroghlanian (2004) and Ali and Elfessi (2004). These results seem to place CAI above the other methods of teaching. It is this basis that Hennessy, et al. (2006) believed that technology supports systematic knowledge construction and application in both curriculum-associated sciences activities and the emerging digital-based technologies.

On the contrary, a study conducted by Bridget, Danner, and Stuckey in 2007 aimed at comparing Virtual Biology and face-to-face laboratories, reported that most students $(87 \%)$ perceived the face-to-face labs as more effective compared to virtual labs counterpart. In the same vein, Spradlin (2009) conducted a study to determine the effectiveness of computer-assisted instruction in developmental mathematics. The study employed the non-randomized control group pretest-posttest design. The study found that the students exposed to the traditional lecture method performed better compared to the experimental group exposed to the computer-assisted instruction. It was concluded that the mere presence of computers does not improve learning and that proper methods should be put in place to ensure effective teaching and learning. For these reasons, Chi-Yan and Treagust (2004) warn that the fact that computers and digital technologies continue to change the appearance of traditional science classrooms does not necessarily mean that learning in the traditional educational environment does not produce tangible results in spite of its weaknesses amid the digital age.

Notwithstanding, the 21st-century teachers are very much keen on using digital and emerging technologies to enrich and improve their teaching and learning environment. The main reason behind this is to enhance teaching to develop students' critical thinking, creative, communication, collaborative skills. These are required in the 21 st-century teaching environment.

\section{Methodology}

\subsection{Study Design}

This study employed the quasi-experimental design. The quasi-experimental design involves a non-equivalent comparison-groups. It is considered to be among the most commonly used quasi-experimental designs. The design is quite similar to the experimental design except that it does not involve in random assignments of research participants to groups. This design uses intact groups as control and experimental groups.

\subsection{Intervention}

The intervention used for the experimental group comprised a PowerPoint presentation (Appendix A), courseware (Appendix B), and YouTube video (Appendix C), all on photosynthesis. The courseware package and video were downloaded from the Internet while the PowerPoint presentation was, however, designed by the researchers. The courseware instruction has been tried, tested and validated. The post-test instrument, Student's Achievement in Photosynthesis Test -SAPT, was administered to all the participants after the intervention.

\subsection{Participants}

The aim of this study was to investigate the impact of multimedia instruction in biology on senior high schools achievement. Elective science students in Senior High Schools (SHS) with computer facilities formed the population of the study. A total of 110 elective biology students were used for this study. This comprised of 53 students from University Practice Senior High School (experimental group) and 57 students from Ghana National College Senior High School (control group). The experimental group was made up of 23 boys and 30 girls while the control group comprised 25 boys and 32 girls. The third-year SHS students were used in the study 
because photosynthesis is taught during the third year of the SHS science programme as it forms part of the SHS 3 elective biology syllabus. Also, SHS 3 students in both selected schools were yet to be taught 'photosynthesis' in elective biology as at the time the study commenced. The distribution of participants in the sample is presented in the table below.

Table 1. Breakdown of Participants for the Study

\begin{tabular}{|c|c|c|c|}
\hline School & $\begin{array}{c}\text { Boys(male) } \\
\text { N (\%) }\end{array}$ & $\begin{array}{c}\text { Girl(female) } \\
\text { N (\%) }\end{array}$ & $\begin{array}{c}\text { Total } \\
\text { N (\%) }\end{array}$ \\
\hline $\begin{array}{c}\text { University Practice Senior } \\
\begin{array}{c}\text { High School } \\
\text { (Experimental Group) }\end{array}\end{array}$ & $23(43.4)$ & $30(56.6)$ & $\begin{array}{c}53 \\
(100)\end{array}$ \\
\hline $\begin{array}{c}\text { Ghana National College } \\
\text { SHS (Control Group) }\end{array}$ & $25(43.9)$ & $32(56.1)$ & $\begin{array}{c}57 \\
(100)\end{array}$ \\
\hline & $48(43.6)$ & $62(56.4)$ & 110 \\
\hline
\end{tabular}

As indicated earlier, in a bid to controlling the factors that affect the internal validity of experimental studies, two groups were used in this study: one experimental group and one control group all of which were intact classes. The experimental group was in University Practice SHS while the control group was in Ghana National College in the Cape Coast Metropolis. These schools were chosen because of the distances between them which did not allow for any interaction that could affect the results of the research. Participants in the experimental group were taught Section Five, Unit Four of the third year SHS elective biology syllabus, which deals with 'photosynthesis', using the multimedia instructional approach. The participants in the control group were also taught the same section and unit of the SHS elective biology syllabus using the traditional instructional approach.

\subsection{Research Instruments}

Two test instruments of comparable standard were used to collect quantitative data from the study participants. The test instruments which were adapted from Yeboah (2010) were named "Students' Knowledge of Photosynthesis Test" - SKPT and "Students' Achievement in Photosynthesis Test" - SAPT. The SKPT and SAPT were used as the pretest and posttest instruments respectively. The SKPT was used to assess the participants' knowledge and difficulty with the concept of 'photosynthesis' to have a baseline about all participants before the implementation of the interventions. The SAPT was, however, designed to measure participants' achievement after the implementation of the interventions. The SKPT and SAPT were both 20 item paper and pencil tests, which were made up of three sections - A, B and C. Section A of each test instruments was a portion that briefly stated the purpose of the test and also asked participants to provide personal data, such as, name, gender, class, and school of participants. This portion also contained general instructions for answering items in all three sections of the test instruments. Additionally, each section of the SKPT (pretest) and SAPT (posttest) begins with specific instructions regarding how to respond to items in that section. Both the SKPT and SAPT were made up of 10 multiple-choice items, followed by four response options Each correct answer circled or chosen attracted one mark, resulting in a total score of 10 marks for section A. Section B was made up of five true-false items, which appeared as items 11 to 15 on the SKPT and SAPT while Section C was made up of five short essay or short - answer items numbered as items.

The tests (Students' Knowledge of Photosynthesis Test SKPT and Students' Achievement in Photosynthesis TestSAPT) were pilot-tested to establish the reliability of the instruments. The test-retest method of reliability was used. The SKPT yielded a correlation coefficient of .60 while SAPT yielded a coefficient of .62 and were considered adequate for the study (Pallant, 2013).

\subsection{Data Collection and Analysis}

Data were collected through the Non-Equivalent Group Design (NEGD) pretest-posttest procedure. The pretest the data collection procedure was divided into three phases: pre-treatment phase, treatment phase, and post-treatment phase. Before the intervention stage, the SKPT (pretest) was administered to both the control group and the experimental group. This test was administered to find out whether both have the same level of understanding regarding Photosynthesis to avoid biases and ensure the groups are homogeneous. The pretest scores were collated and analysed (see Table 2) to determine the homogeneity of the group and to make way for the intervention stage of the study. The data was collected in a space of three weeks. At the school where the experiment took place, the downloaded interactive video on photosynthesis and the interactive courseware were made available on all computers at the school's computer laboratory. This was to make the intervention easily accessible to students. The researchers used the already prepared PowerPoint presentation to teach for a week. During the second week, students were taken through the interactive courseware and the YouTube video at the computer laboratory. The third week was used to assess students' achievements in both groups. Both the pretest and posttest in the control and experimental groups took proximately 1 hour. The SAPT was administered to the participants not long after the intervention to prevent time-related effects that could confound the results. 
Table 2. Difference in Pretest scores between the Control and Experimental Groups

\begin{tabular}{|c|c|c|c|c|c|c|c|c|}
\hline Group & $\mathrm{N}$ & Mean & $\mathrm{SD}$ & Range & mode & $\mathrm{t}$ & $\mathrm{df}$ & sig \\
\hline Control group & 57 & 12.3 & 2.48 & 11 & 13 & \multirow{2}{*}{.539} & \multirow{2}{*}{52} & \multirow{2}{*}{.592} \\
\cline { 1 - 6 } Experimental group & 53 & 12.6 & 2.98 & 11 & 10 & & & \\
\hline
\end{tabular}

\section{Results}

\subsection{Test of Homogeneity of the Groups}

The first objective sought to determine the comparative nature of the group before the intervention was introduced. The SKPT was administered and the results analysed. The results for both groups were normally distributed. Therefore, the pretest scores of the control group and the experimental group were analysed using paired-samples $t$-test and the results are shown in Table 2 .

The data presented in Table 2 show that, in the pretest, the control group obtained a mean score of $12.3(S D=2.48)$ and mode of 13 while the experimental group obtained a mean of $12.6(S D=2.98)$ with a mode of 10 . However, both groups obtained equal range (11). It also shows that the majority of students in the control group scored 13 while a majority in the experimental group scored 10. However, there was no significant difference in the pretest scores between the control group and the experimental group, $t(52)=.592, p=.59$. This suggests the control and the experimental groups were homogeneous in terms of achievement.

\subsection{Effect of the Interactive Multimedia on Students Achievement}

The second focus of the study was to investigate the effect of multimedia on students' academic achievement. The differences in posttest score between the control and experimental groups were explored and results presented in Table 3.

The results in Table 3 show a statistically significant difference in posttest mean scores between the control group and experimental group, $t(52)=-3.91, p<.05$. The results show that students who were taught with the interactive multimedia achieved better $(\mathrm{M}=23.32, S D=3.17)$ compared to the group taught with the conventional lecture method $(M=20.37, S D=4.45)$, that is, the control group. The results suggest that the use of interactive multimedia had a significant effect on students learning of Photosynthesis compared to the traditional method.

\subsection{Influence of Gender on Students Achievement}

The study also explored the influence of gender on students' achievement after the introduction of the interventions. This aimed at finding out differences in achievement scores between male and female students taught with the interactive multimedia approach and those taught using the traditional lecture approach. The results are available in Table 4.

The results from the independent-samples $t$-test as shown in Table 4 indicate that gender did not have significant influences on students' taught with the interactive multimedia, $t(51)=.033, p=.97$. Although the mean scores of males $(\mathrm{M}=23.33, S D=2.73)$ and that of females $(M=23.30, S D=3.73)$ appear different on the face value, the difference was not significant. It can therefore be concluded that this did not influence students' posttest scores.

On the contrary, in the control group, the data show there exists a statistically significant difference between males and females concerning the posttest scores of, $t(55)=-2.22$, $p=.024$. It was found that the females $(M=21.50, S D=4.23)$ performed better than their male counterparts $(M=18.92$, $S D=4.53$ ). It can be concluded that gender had a statistically significant influence on students' achievement scores in the control as opposed to the experimental group.

Table 3. Difference in Posttest Scores between Control and Experimental Groups

\begin{tabular}{|c|c|c|c|c|c|c|c|c|}
\hline Group & $\mathrm{N}$ & Mean & SD & Range & Mode & $t$ & df & Sig. \\
\hline Control group & 57 & 20.37 & 4.45 & 15 & 19 & \multirow{2}{*}{-3.915} & \multirow{2}{*}{52} & \multirow{2}{*}{.000} \\
\cline { 1 - 7 } Experimental group & 53 & 23.32 & 3.17 & 16 & 25 & & \\
\hline
\end{tabular}

Table 4. Difference in Students Posttest Achievements Scores by Gender

\begin{tabular}{|c|c|c|c|c|c|c|c|c|}
\hline Group & Gender & $\mathrm{N}$ & Mean & SD & $F$ & $t$ & df & Sig.(2-tailed) \\
\hline \multirow{2}{*}{ Experimental group } & Male & 23 & 23.33 & 2.73 & \multirow{2}{*}{3.34} & \multirow{2}{*}{.033} & \multirow{2}{*}{51} & \multirow{2}{*}{.971} \\
\hline & Female & 30 & 23.30 & 3.73 & & & & \\
\hline \multirow{2}{*}{ Control group } & Male & 25 & 18.92 & 4.53 & \multirow{2}{*}{.009} & \multirow{2}{*}{-2.25} & \multirow{2}{*}{55} & \multirow{2}{*}{.024} \\
\hline & Female & 32 & 21.50 & 4.13 & & & & \\
\hline
\end{tabular}




\section{Discussion}

The importance of the use of multimedia in teaching and learning cannot be underestimated. Much importantly so when it comes to science-based subjects that are sometimes considered more abstract in content and difficult to grasp. Many studies have acclaimed the innovating effects of computer-based instruction (Labus, Despotovic-Zrakic', Radenkovic, Bogdanovic', \& Radenkovic, 2015). For instance, in a study conducted by Labus et al. (2015) on the possibilities of improving the formal eLearning process with informal game-based learning on social media. A sample of 240 undergraduate students was used for the study. This sample was randomly divided into an experimental group (120 participants) and control group (120 participants). The study found that the experimental group that used the Elab Game achieved better results than the control group. The participants of the experimental group acknowledged that the use of edutainment in learning is interesting and motivating. This study's findings align with a study that found that interactive multimedia had a significant influence on students learning in Biology, specifically, photosynthesis. Julius, Twoli and Maundu (2018) conducted a similar study in Kenya in Chemistry which is somehow closely related to the current study. The study investigated the effect of Computer-Aided Instruction (CAI) on students' achievement in Atomic Structure Periodic Table and Chemical families as against the use of the conventional instructional method (CIM). It was found that the students who were taught with the CAI obtained higher scores on the posttest compared to those using the CIM. Furthermore, Jesse, Twoli, and Maundu (2015) add to the success story of the use of computers in teaching and learning science-related courses. They concluded in their study on the combined effect of computer-assisted in instruction in the teaching of Biology, Physics, and Chemistry that CAI improves secondary students learning in the sciences. Similar findings were also recorded in Gambari et al. (2014), and Quarcoo-Nelson et al. (2012) in Biology and Physics. This goes to underscore the impressive power and role of computers in education. Although computers are powerful in terms of their ability to deal with large data, their effective application in education is dependent on several factors such teacher's technological pedagogical content knowledge (TPACK). This is because different approaches are needed where facilitation of educational transaction is conducted through technology (Zainuddin \& Idrus, 2017).

Surprisingly, in a paper presented in Nigeria, Tukur, Yunusa, and Isiyaku in 2014 found conflicting results to the current study's. Their study found no significant difference between CAI and CIM in teaching, which suggest that CAI did not have a significant effect on students' learning compared to traditional instruction. They, however, attributed their findings to students' familiarity with computers and cognitive strategies. This implies that computer-assisted instruction is as good as the conventional teaching method (Tukur et al., 2014)

Students' demographics play a key role in determining the effectiveness of instructional methods. Especially, gender and age have featured prominently in most studies either as independent or intervening variables. This study also investigated how gender influence on students' achievement scores both in control and experimental groups. It was revealed that although the gender of respondents did not have a significant influence on students' performance among students taught with the interactive multimedia (CAI), gender effect was conspicuous in the control group where females obtained significantly better results compared to males. Besides, in the experimental group, female students performed marginally better than their male counterparts although not significant.

\subsection{Conclusions and Recommendations}

Based on the findings recorded in this study, it is concluded that the use of interactive multimedia in the teaching of Photosynthesis significantly improves students' achievements compared to the use of conventional instructional methods. It must, however, be stated that in spite of these impressive results of CAI, the importance of the conventional method of teaching should not be underrated. The results showed that although students exposed to the multimedia performed better than those taught through the conventional method, some gains were made by those who used conventional instruction. Furthermore, this study concludes that there is no significant difference in students' achievements in Photosynthesis between males and females regarding those exposed to multimedia instruction. It believed that females tend to shy away from technology, specifically computers, compared to their male counterparts. This study has shown that when technology is used to innovate the classroom there would be no significant difference in achievements between males and females. This suggests that the use of CAI in teaching such abstract topics is gender-friendly since it favours both males and females. Undoubtedly, digital technologies continue to change and revolutionize education not only in the advanced countries but also in the developing world. With the numerous internet resources available with the click of a button, teachers should continually find new ways to innovate the science classrooms to make them quite interesting to students. This will make science courses pleasurable to pursue. The current study interestingly recorded a significant difference in achievement scores between males and females in the control group that used the traditional method of teaching. In that regard, it can be concluded that the traditional methods of teaching tend to favour a particular gender, especially, males. It is recommended that teachers should continually expose students to multimedia instructional 
strategies (MIS) to promote effective and active learning and learning by experience among students. This will not only improve learning but also instill self-confidence, self-motivation, self-wealth in learners and develop a positive attitude toward learning. Besides, teachers should use different approaches to teaching to reach out to students with different learning styles. This will go a long way to improve the performance of students. Another area that could be explored due to lack of attention by researchers in the developing countries has been the use of learning management systems (LMSs) in teaching at the secondary school level. The current study recommends that researchers turn their attention to explore the possibility of using LMSs at the secondary schools which would help in developing students' 21 st-century skills which are required to be exhibited by the young one.

\section{Appendix}

\section{Appendix A: A Picture of the Photosynthesis Courseware Used as Treatment}

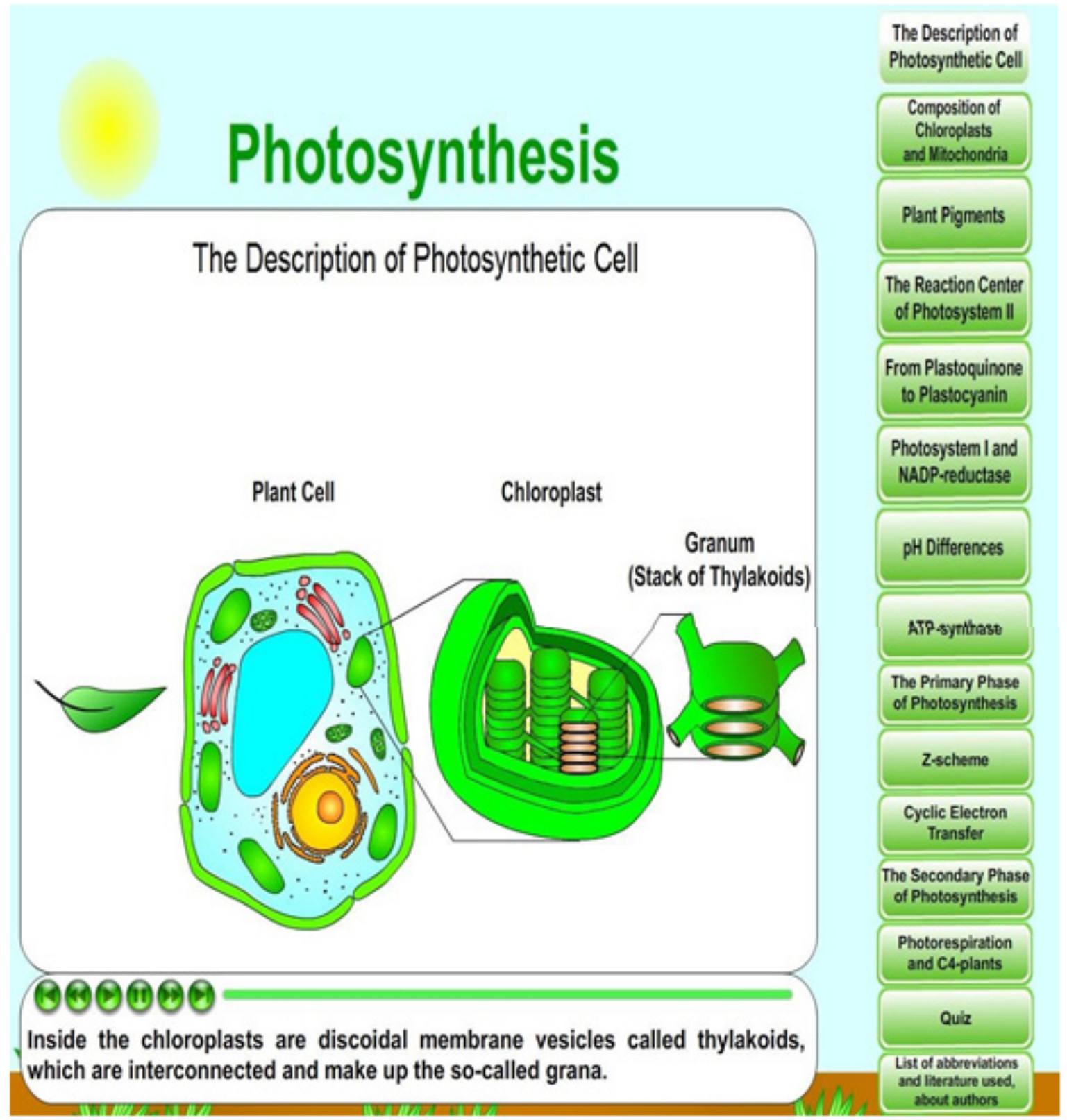


Appendix B: Screen Captured Picture of Power Point Presentation Lesson on Photosynthesis

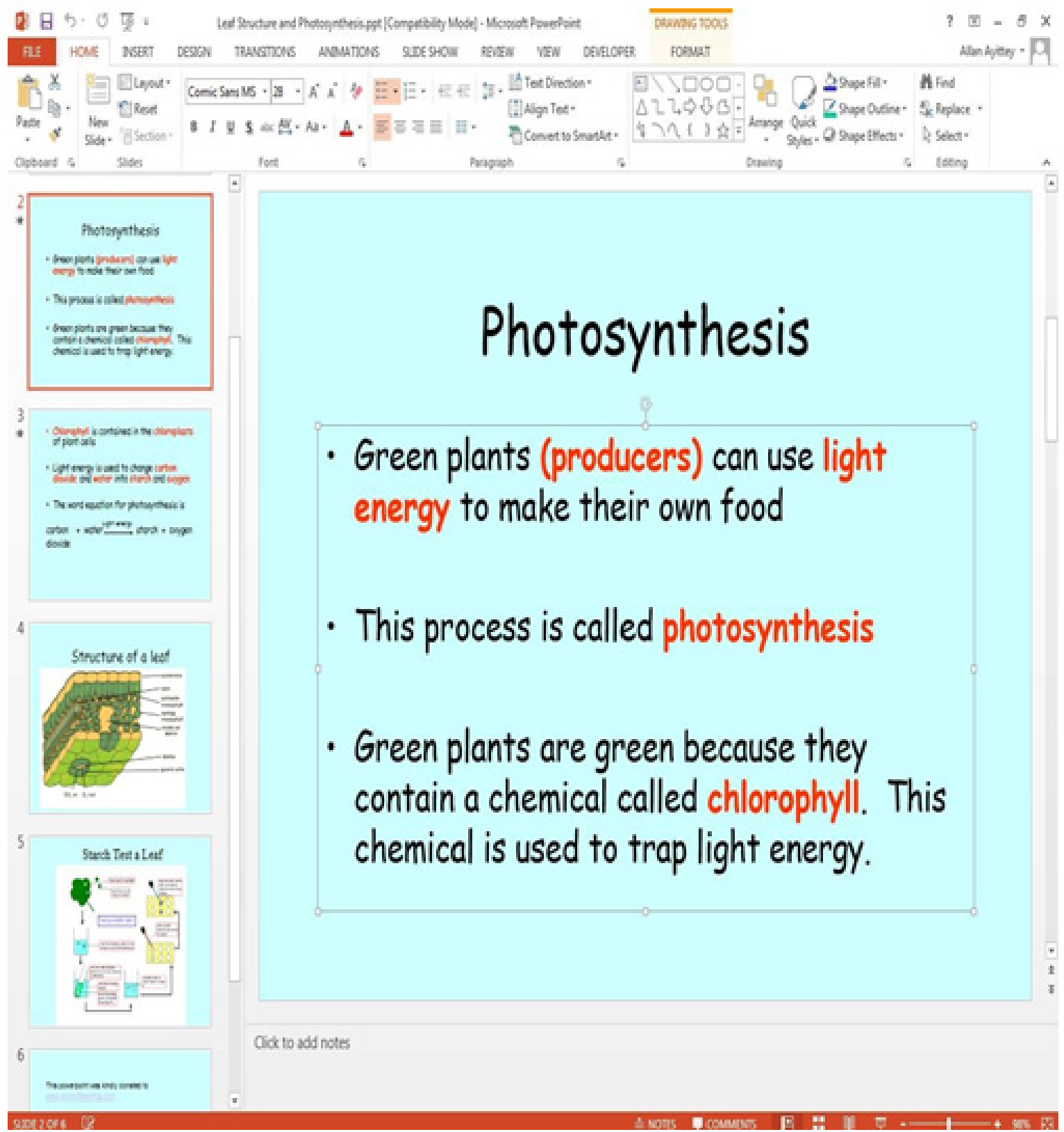


Appendix C: Screen Captured Picture of Video Based Lesson on Photosynthesis

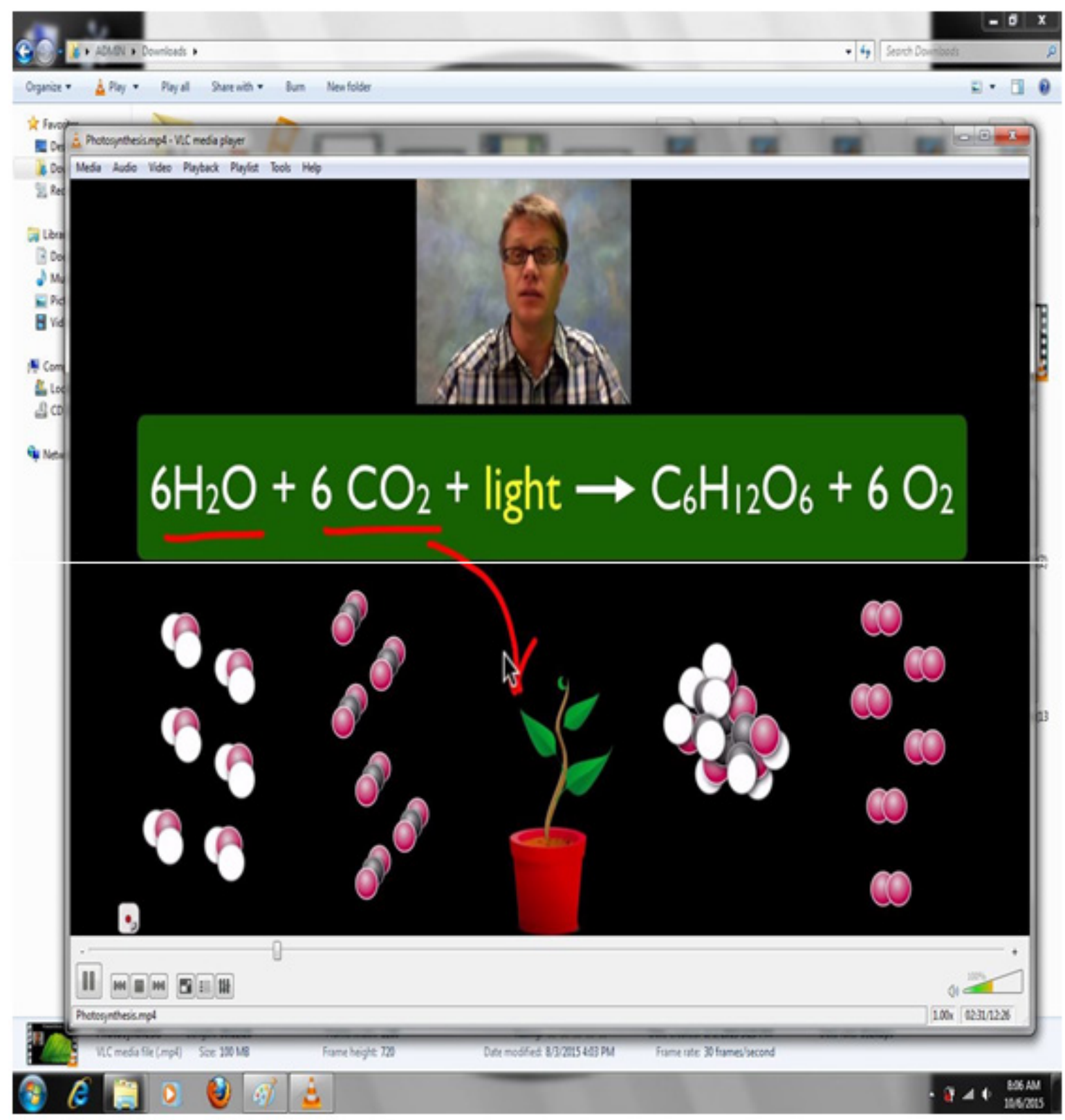




\section{REFERENCES}

[1] Acha, J. (2009). The Effectiveness of Multimedia Programmes in Children's Vocabulary Learning. British Journal of Educational Technology, 40(1), 23-31. Retrieved from http://blackwellpublishing.com/jnl_default.asp

[2] Adegoke, B. A. (2011). Effect of multimedia instruction on senior secondary school students' achievement in physics, European Journal of Educational Studies 3(3), 537

[3] Ahmed, M. A. (2008). Influence of personality factors on biology lecturers' assessment of difficulty levels of genetics concepts in Nigerian colleges of education (Unpublished doctoral thesis). University of Ilorin, Ilorin, Nigeria.

[4] Ahmed, M. A., \& Abimbola, I. O. (2011). Influence of teaching experience and school location on biology teachers' rating of the difficult levels of nutrition concepts in Ilorin, Nigeria. JOSTMED, 7(2), 52-61

[5] Ajayi, D. O. (1998). Community science: Implications for science teacher: Proceeding of the 39th Annual Conference of STAN. Obtained October 2015 from http://www.ijern.c om/journal/2014/November-2014/18.pdf

[6] Bridget D. S., Danner, T. A., Stuckey, M. (2007). Virtual Labs in the Online Biology Course: Student Perceptions of Effectiveness and Usability. MERLOT Journal of Online Learning and Teaching, 3(2), Retrieved from http://jolt.me rlot.org/vol3no2/stuckey

[7] Chi-Yan T. W., \& Treagust, D. (2004). Motivational aspects of learning genetics with interactive multimedia. American Biology Teacher, 66(4), 277-285.

[8] Cockerill, M., Comeau, T., Lee, T. H., \& Vinayak, J. (2015). Utilizing Video Multimedia Tools in Biology Labs, Project EL08. Retrieved from www.wpi.edu

[9] Ellaisamy, M. (2007). Effectiveness of Multimedia Approach in Teaching Science at Upper Primary Level. Indian Educational Review, 43(1). NCERT, New Delhi

[10] Feeg, V. D., Bashatah, A., Langley C. (2005). Development and testing of a CD-ROM based tutorial for nursing students: getting ready for HIPAA. The Journal of Nursing Education, 44(8), 381-6. Retrieved from: https://www.ncbi .nlm.nih.gov/pubmed/16130345

[11] Fenrich P. (2007) Practical Guidelines for Creating Instructional Multimedia Applications (1st ed.). Harcourt College Pub: Port Harcourt.

[12] Gambari, A.I., Yaki, A.A., Gana, E.S. \& Ughovwa, Q.E. (2014). Improving Secondary School Students' Achievement and Retention in Biology through Video-Based Multimedia Instruction. InSight: A Collection of Faculty Scholarship, 9, 78-91. Retrieved from https://www.learntechlib.org/p/156435/.

[13] Hennessy, S., Deaney, R., \& Ruthven, K. (2006). Situated expertise in integrating use of multimedia simulation into secondary science teaching. International Journal of Science Education, 28(7), 701-732.

[14] Jian-hua, S., \& Hong, L. (2012). Explore the Effective Use of Multimedia Technology in College Physics Teaching. Energy Procedia, 17, 1897-1900. https://doi.org/10.1016/j. egypro.2012.02.329

[15] Jesse, S. N., Twoli, N. V., \& Maudu, J. N. (2015). Enhancement of Science Performance through Computer-Assisted Instruction among Selected Secondary School Learners in Kenya. Kentucky Journal of Excellence in College Teaching and Learning, 12(4), 39-51. Retrieved from https://encompass.eku.edu/kjectl

[16] Julius, J. K., Twoli, N. W., \& Maundu, J. N. (2018). Effect of Computer Aided Instruction on Students' Academic and Gender Achievement in Chemistry among Selected Secondary School Students in Kenya. Journal of Education and Practice, 9(14), 56-63.

[17] Kareem, A. (2003). Computer-Assisted Learning: Cyber Patient-A. Step in the Future of Surgical Education. J Invest Surg, 12(6), Pp. 307-317.

[18] Klein, J., \& Koroghlanian, C. (2004). The Effect of Audio and Animation in Multimedia Instruction. Journal of Educational Multimedia and Hypermedia, 13(1), Pp. 23-46. Retrieved May 2015 from http://www.editlib.org

[19] Krstev, C., \& Trtovac, A. (2014). Teaching Multimedia Documents to LIS Students. The Journal of Academic Librarianship, 40(2014), 152-162. Retrieved from https://doi.org/10.1016/j.acalib.2014.02.006

[20] Kumar, K.S. K. (2011). Teaching Grammar through Multimedia to Rural Secondary School Students. Indian Streams Research Journal, 1(4), 22-36. Retrieved Septemb er 2015 from http:// www.isrj.net

[21] Kuti, J. B. (2006). Effect of multimedia instructional strategy on Senior Secondary Students' learning outcomes in Physics in Ogun State, Nigeria (Unpublished master's project).

[22] Labus, A., Despotovic-Zrakic', M. Radenkovic, B., Bogdanovic', Z., \& Radenkovic, M. (2015). Enhancing formal e-learning with edutainment on social networks. Journal of Computer Assisted Learning, 31, 592-605.

[23] Mangesi, K. (2007). ICT in Education in Ghana. Survey of ICT and Education in Africa: Ghana country report. Retrieved on July 2015 from www.infodev.org

[24] Maor, D., \& Fraser, B.J. (1996). Use of classroom environment perceptions in evaluating inquiry-based computer-assisted learning. International Journal of Science Education, 18, 401-421

[25] Mishra, S., \& Sharma, R. C. (2005). Interactive Multimedia in Education and Training. IGI Global,

DOI:10.4018/978-1-59140-393-7. Retrieved from www.researchgate.net

[26] Owusu,K. A. (2009). Effects of computer-based learning on senior high school students' achievement in biology. Unpublished master's thesis, University Of Cape Coast, Cape Coast

[27] Pallant, J. (2013). SPSS Survival Manual. UK: McGraw-Hill Education.

[28] Paris, P. G. (2004) E-Learning: A Study on Secondary Students' Attitudes towards OnlineWeb Assisted Learning. International Education Journal, 5(1), 98-112. 
[29] Persin, R. (2002). Web-Assisted Instruction in Physics: An Enhancement To Block Scheduling. American Secondary Education, 30(3), 61-69.

[30] Phillips, R. (1997). The Developers handbook to Interactive Multimedia: A Practical Guide for Educational Applications. London: Kogan Page. Retrieved form http://www2.plymouth.ac.uk/ed/ELT\%20documents/mater ials/Bibliography.pdf

[31] Quarcoo - Nelson, R., Buabeng,, I., \& Osafo, D. K. (2012). Impact of Audio-Visual Aids on Senior High School Students' Achievement in Physics. Eurasian Journal of Physics and Chemistry Education, 4 (11), 46 - 54.

[32] Sangodoyin, A. (2010) Computer Animation and the Academic Achievement of Nigerian Senior Secondary School Students in Biology. Journal of the Research Center for Educational Technology. 6(2), 148-157.

[33] Slack, R. (1999) PEDACTICE - The Use of Multimedia in Schools No. 17. Retrieved from: http://www.eurasianjourn als.com/index.php/ejpce

[34] Tukur, A. K., Yunusa, A. A., \& Isiyaku, A. (2014). Impact of computer-assisted instruction (CAI) and school type on students academic performance in basic technology in Sokoto State, Nigeria. Paper Presented at the 35th Annual Workshop and Conference of Nigerian Association of Educational Media and Technology (NAEMT) at the University of Port Harcourt, Nigeria., October, 2, 0-16.

[35] Umar, A. A. (2011). Effects of biology practical activities on students' process skill acquisition in Minna, Niger State, Nigeria. JOSTMED, 7(2), 118-126.

[36] West African Examination Council, Ghana. (2002). Chief Examiners' reports. Ghana: WAEC. Retrieved from: https://ghana.waecdirect.org/indexverify.htm

[37] West African Examination Council, Ghana. (2003). Chief Examiners' reports. Ghana: WAEC. Retrieved from: https://ghana.waecdirect.org/indexverify.htm

[38] West African Examination Council, Ghana. (2004). Chief Examiners' reports. Ghana: WAEC. Retrieved from: https://ghana.waecdirect.org/indexverify.htm

[39] West African Examination Council, Ghana. (2005. Chief Examiners' reports. Ghana: WAEC. Retrieved from: https://ghana.waecdirect.org/indexverify.htm

[40] West African Examination Council, Ghana. (2011). Chief Examiners' reports. Ghana: WAEC. Retrieved from: https://ghana.waecdirect.org/indexverify.htm

[41] Yeboah, O. S. (2010). The effect of computer simulation on the teaching and of photosynthesis at the senior high school level in the Accra Metropolis. Unpublished thesis University of Education, Winneba. Retrieved from https://independent.academia.edu

[42] Yeboah, A. E. (2014) Applying ICT in Biology. Unpublished Project work. University of Education, Winneba.

[43] Yusuf, M O., \& Afolab, A. O. (2010) Effects of computer assisted instruction (CAI) on secondary School students' performance in biology. TOJET: The Turkish Online Journal of Educational Technology, 9(11). Retrieved from http://wwww.tojet.edu.com
[44] Zainuddin, N., \& Idrus, M. R. (2017). From TPACK to learning buffet: Developing a new model for open and flexible learning. Saudi Journal of Humanities and Social Sciences, 2(4), 344-347. 